\title{
An Analysis of the Problems and Countermeasures in the Application of Experiential Marketing - A Case Study of Starbucks
}

\author{
Yajuan Liu $^{1, a^{*}}$ and Ping Gui ${ }^{2, b}$ \\ ${ }^{1,2}$ School of Management, Wuhan University of Technology, Wuhan, China

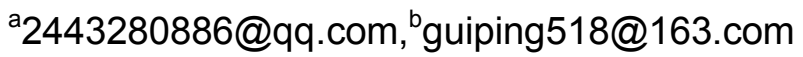

Keywords: Experiential marketing, Starbucks, Starbucks experience, Problems, Countermeasures

\begin{abstract}
With the rapid development of China's economy, people's living standards continue to improve. People are increasingly pursuing spiritual need, consumers seem to pay more attention to experience, which has a huge experience of the consumer market. With the advent of experiential economy, experiential marketing is widely used in all walks of life. But some companies only focus on the form of experiential marketing, while ignoring the real feelings of consumers, and did not maximize the value of consumer experience. Therefore, this paper takes Starbucks as an example. Firstly, the paper introduces the successful mode of experiential marketing. Secondly, it points out the problems of Starbucks experience. Next, it puts forward the corresponding measures. Finally, some suggestions are made for Chinese enterprises to carry out experiential marketing activities to win the initiative in the fierce market competition.
\end{abstract}

\section{Introduction}

With the increasing standard of living, consumers' ideas are changing, they are not paying attention to the functional benefits that products or services bring to them, and they emphasize the experience during the purchase and consumption of products or services [1]. The foreign scholar Schmidt first introduced the concept of experiential marketing, and he argued that experiential marketing was a way for marketing staff to create a combined effect to increase the customer experience through a variety of means and approaches (facilities, products, services, interactions, etc.)[2]. Pine and Gilmore think that experiential marketing is redefined and designed from the consumer's senses, emotions, minds, actions, and coordination. They think that consumers are both rational and sensible, consumer experience is the key to study consumer behavior and corporate brand management [3]. Chinese scholar Wang Tao believes that experiential marketing is a management activity, which is the enterprise through the customer experience and the corresponding scenes and events to attract customers immersed in this event, giving a deep impression. In other words, experiential marketing is a way of thinking marketing through the means of look, listen, use, participation.

In summary, this paper defines the experiential marketing: enterprises set a certain theme of the experience, so that consumers take the initiative to participate in the experience activities, which leave a good impression about the product or service for customer and meet their psychological needs. Starbucks experience is a successful example of experiential marketing. How did Starbucks succeed? What are the problems in the application of experiential marketing? The following will be a detailed analysis of its experiential marketing, hoping to give inspiration to China's enterprises.

\section{Starbucks Experience Marketing}

Starbucks was founded in 1971, initially as a small local coffee shop in Seattle. It became an international coffee chain just for 20 years' development, known as the "20th century American business legend [4]." The Table 1 summarizes the changes of the marketing of Starbucks in the changing economy [5]. 
Table 1 The Change of marketing of Starbucks Company

\begin{tabular}{|c|c|c|c|c|}
\hline Economy & Agriculture & Industrial & Service & Experience \\
\hline Marketing & \multicolumn{2}{|c|}{ Traditional Marketing } & Service Marketing & Experiential Marketing \\
\hline Product & Commodities & Goods & Service & Experience \\
\hline Characteristics & $\begin{array}{r}\text { Tangible products, Feature and } \\
\text { benefits of the products }\end{array}$ & Customized service & $\begin{array}{c}\text { Expressive, Personal } \\
\text { experience }\end{array}$ \\
\hline
\end{tabular}

In the era of experiential economy, Starbucks uses the strategy of experiential marketing and has achieved great success, as follows:

Emotional Experience. Starbucks employees treat customers as friends, and they can call out the name of the old customer, so that customers feel that they are taken seriously. For the needs of customers, Starbucks employees are always smiling, people feel relieved and relaxed. This enhances the emotional interaction between employees and consumers, satisfies customers and spreads Starbucks coffee culture.

Product Experience. Starbucks insists on choosing the best coffee beans from the best coffee source. In the procurement of coffee beans, selection, transportation, baking, deployment, sales, etc., has a very strict standard [6]. On product innovation, to provide customers with a variety of product experience, so that customers have a worthwhile travel.

Service Experience. Starbucks is not a service-oriented coffee company, but a coffee service company. Requiring employees to receive professional training before work. It has a special service - "coffee classroom", professional barista to explain the coffee culture and knowledge to customers, so that customers get unexpected harvest and service experience. In terms of financial services, Starbucks has introduced prepaid cards to provide convenience to customers, greatly reducing checkout times [7].

Sensory Experience. After entering the Starbucks store, you can see all kinds of ancient wooden tables and chairs, soft lighting, a portrait of the humanities, listen to the light music, smell the fragrant coffee, sit down and buy a cup of coffee to drink. Customers are infected by this atmosphere when they enter the coffee store, people feel relaxed, temporarily forget the trouble[8].

Interactive Experience. Starbucks interactive experience is reflected in the shop interior experience and shop extension experience [9]. In-store experience has been reflected in the above experience, here focus on shop extension experience. Starbucks created a star club, allowing all stars to communicate with each other, sending e-mail and birthday wishes to them, and more closely with the customer's relationship. Starbucks has developed a mobile phone APP, for the customer online booking provides a convenient. Starbucks designs magazines carefully, so fans know the latest information. But also to provide outside activities, such as coffee exchange, public welfare activities, travel experience. Strengthen interaction with customers so that it has a deeper understanding of Starbucks, enhance customer loyalty.

\section{Problems on Starbucks Experience Marketing}

In recent years, Starbucks experience marketing also appeared some problems, affecting the company's progress and development, as follows:

Experience Desalination. The "Forbes" two weeks of the site published an article entitled "Starbucks in China under the seeds of self-destruction: rotten street [10]". The report reflected the self-brand devaluation of Starbucks over-expansion. As early as 2008, due to rapid expansion, Starbucks has been facing operational difficulties. Starbucks gradually ignored the customer's intentions - to experience Starbucks experience.

Quality Problems. With the continuous development of Starbucks, and constantly expand the product line, during which there have been some problems. Starbucks used trans-fatty acids in the production of donuts, muffins and other pastries; "moon cake events", the main quality problems are The total number of colonies exceeded, excessive acid value and labeling are not standardized and so on. This seriously affected the development of Starbucks, its expansion should also focus on 
quality and safety, otherwise its brand will be greatly affected.

Service Quality Declined. Due to the rapid expansion of Starbucks and the assurance of financial objectives, the original service experience process is mostly replaced by pipeline operations, customer participation and experience are also gradually reduced. In order to complete tasks and performance, employees pursue speed excessively, and interaction is not as frequent as before. Lacking communication led less understanding of the real needs of customers, service quality declining, which let customers feel nothing about Starbucks experience virtually, to some extent, reducing customer loyalty and satisfaction.

Corporate Culture Weakened. Starbucks business philosophy is caring employees, and employees take care of customers. In other words, Starbucks external experience can be based on internal marketing. Starbucks has a cultural tradition that employees should be trained in the headquarters for three months before opening. Now the tradition has gone. Due to large-scale expansion, staff training efforts and welfare measures have declined as before, staff enthusiasm is reducing and the interaction with customers is also reducing, which leading declined customer satisfaction and profit. Emphasizing employees of the corporate culture is the core competitiveness of enterprises. Therefore, Starbucks need to pay attention to the re-shaping of corporate culture.

\section{Suggestions on Starbucks Experience}

Retain Starbucks Characteristics, Localize Appropriately. Due to national conditions or consumption habits are different, some consumers may not want to try. Therefore, the need for in-depth study of Chinese culture before entering the market, to understand their consumer values, habits preferences, needs and spending power. Therefore, Starbucks can retain its own characteristics in the case, adding more Chinese elements for a comprehensive localization consumption environment, taste and habit of localization; enriching and expanding the product line to meet different consumer needs; pulling the price level to meet different consumer choices.

Control the Expansion Speed, Ensure the Core Competitiveness. In recent years, due to excessive expansion of Starbucks, the number of staff is rising, including some part-time staff, these people are more mobile, not conducive to maintaining feelings with customers. Starbucks experience is fundamental, otherwise, resulting in decreased customer loyalty and profits. Therefore, Starbucks should control the expansion rate, select staff strictly, train professionally, concern about the customer feeling and experience and strengthen customer maintenance to ensure the core competitiveness of enterprises.

Keep in Mind Social Responsibility, Improve Brand Awareness. Starbucks brand known by the public quickly is related to what Starbucks does plenty of charity events. For example, recycling Starbucks Cups; funding children in poverty-stricken areas to school; saving water, energy, more than 1 million hours per year for community services so that reduces the burden of the planet. But in recent years, Starbucks pay too much attention on business interests, appearing a lot of quality problems and ignoring social responsibility. Concerning social responsibility can enhance brand awareness, which is good to obtain the brand effect without advertising. Therefore, Starbucks should bear in mind social responsibility and improve brand awareness and reputation, which is conducive to its long-term development.

Focus on Corporate Culture, Improve Service Quality. Starbucks culture is inseparable from its products, employees, services, experience, innovation and public service. Therefore, Starbucks should re-establish the original cultural tradition, sharing Starbucks culture and knowledge with employees in the morning meeting and summarizing the lack of work in the morning meeting, which enhancing the sense of belonging of staff and spreading corporate culture well. In addition, Starbucks should also improve the quality of service, thereby improving customer satisfaction and loyalty.

Maintain Corporate Image, Customer-Oriented. In order to achieve profit targets and economies of scale, Starbucks expands rapidly, resulting in a lot of product quality problems and leaving a negative impression on customers, so that old customer loyalty declines and potential customers hold skeptical attitude. Therefore, Starbucks should treat customer as a fundamental, 
strengthening product quality and safety, and supervision of work to maintain a good corporate image.

\section{Suggestions on Chinese Enterprises}

Through the analysis of Starbucks experience, the following suggestions are made to inspire our enterprises.

Change the Traditional Idea, Establish the Concept of Experiential Marketing. In the era of experiential economy, consumers are changing the concept of consumption. But many China's enterprises still stay in the traditional marketing concept stressed the value of the product itself and features, ignoring the real feelings of consumers. Therefore, China's enterprises should actively change the traditional marketing concept, customer-centric, so that customers take part in and experience the design of the activities of enterprises actively.

Develop Appropriate Experiential Projects, Enhance Interaction with Consumers. First, enterprises should be based on their own resources and ability to select the experiential project. Second, consider whether there is support for the carrier. For example, the product itself, the consumer environment, market purchasing power, product technology or industry maturity and stability. Next, adding the corporate culture into customer experience, from the spiritual level to impress consumers. Finally, it is the appropriate interaction with the consumer. Truly understand the experience and needs of consumer, at the right time to give customers a certain guide, do not completely ignored or "push" type of experience marketing.

Use Experiential Marketing Appropriately in the Marketing Strategy Combination. After clearing and establishing the concept of marketing experience, it is necessary to develop experiential marketing strategy. Generally from the product, price, channel, promotion of four aspects of the application of marketing strategy portfolio. If is the service catering industry, it should also consider the physical display, personnel, projects, services and so on, which is based on the specific circumstances to apply marketing strategy portfolio.

Analyze Customer Psychological Needs, Win Customer Trust. Customer psychology is the most elusive, but also the last line of defense. Enterprises need to catch the customer psychology, taking into account what customer concerns, such as price, family or educational factors to help customers solve the problem, then customers will trust you and your products from the heart. At this time, no matter how difficult the customer encountered, he will find ways to buy this product. Therefore, companies should pay more attention to analyze the psychological needs of customers, winning the trust of customers, the transactions will follow [11].

Maintain Corporate Brand, Improve Service Quality. Due to excessive expansion, Starbucks brand is damaged greatly. It is very important to maintain the brand. Therefore, enterprises should notice to promote and maintain corporate brand during the implementation of experiential marketing, but also improve the quality of service, if customer satisfaction is high, there will have a good reputation. Maintaining the corporate brand and improving the quality of service is complementary[12].

Shape the Culture of Experience, Ensure the Core Competitiveness. No culture of the nation is terrible, so enterprises are. To provide consumers with a unique experience culture, our enterprises should develop the theme of the experience and add own corporate culture, which has a subtle influence on the customer's way of thinking, awareness activities and practical activities in order to ensure the core competitiveness of enterprises and enhance customer loyalty.

Establish Customer Database, Achieve the Network of Experiential Marketing. Technology development is changing, the network has been very popular. Enterprises should establish their own customer database, analyze customer information carefully and develop appropriate experience services for them, sending the latest product information, caring messages and small gifts for customers regularly, but also focus on communication and interaction with customers.

Improve Innovation Ability, Advance with the times. Innovation is national progressive soul and is the first productive force. For business, innovation is the key to its success. Starbucks' innovation is more far than its competitors in products, technology and services. Therefore, China's 
enterprises should increase the investment of scientific and technological innovation and R \& D, focus on market research and customer experience, create what customer needs and advance with the times.

\section{Conclusions}

Experiential marketing as a new marketing model, the core is to attract consumers to participate actively in a full range of experience. Starbucks experience can be summarized as the following points: First, first-class quality assurance, including high-quality coffee, intimate service and unique sensory experience. Second, focus on customer experience and interaction. Finally, care for employees. Therefore, China's enterprises should take into account the rational side of the consumer, but also take into account its emotional side during the implementation of experiential marketing, pay attention to the two-way communication with consumers. Through a variety of ways to provide consumers with a variety of characteristics of the experience to meet the changing needs of consumers, so that experiential marketing be an important way to enhance consumer satisfaction and loyalty for Chinese enterprises.

\section{Acknowledgements}

Research on the Countermeasures of Accelerating the Development of Science and Technology Insurance in Hubei Province Fund Project (20162s0065)

\section{References}

[1] J. Yao, X. Gao: Guide to Business, Vol. 17(2016) No.4, pp.92-93. (In Chinese)

[2] B. H. Schmitt: Experiential Marketing: How to Get Customers to Sense , Feel, Think , Act , and Relate to Your Company and Brands. (The Free Press, New York 1999)

[3] Y.L. Xia, W. Lu: Experience the Economy. (Mechanical Industry Press, Beijing 2002)

[4] Information on http://www.starbucks.cn

[5] Y.J. Jang, E.C. Jung: Springer Berlin Heidelberg, Vol. 2013, 8015:30-36

[6] S.Y. Wu: Foreign Economic Relations \& Trade, Vol.26 (2012) No.8, pp.113-114. (In Chinese)

[7] B Schmitt. Experience Marketing: Concepts, Frameworks and Consumer Insights. Foundations \& Trends ${ }^{\circledR}$ in Marketing, 2011, 5(2):55-112

[8] X.R. Zhang: Starbucks (China) marketing strategy analysis (MS. Jilin University, 2014) ,p.30.

[9] Y.C. Zhou: Business, Vol. (2015) No.36, p.101. (In Chinese)

[10] Information on http://finance.cnr.cn

[11]P.P. Kang: China Journal of Commerce, Vol. 24(2015) No.13, pp.7-8+20. (In Chinese)

[12]G.F. Shi, D.M. Chen and K.L. Tao: China Management Informationization,Vol.12 (2016)No.12, pp.66-67.(In Chinese) 